\title{
Comparison of Gas Dehydration Methods based on Energy Consumption
}

\author{
KINIGOMA, BS; ANI, GO \\ Department of Petroleum and Gas Engineering, \\ University of Port Harcourt, Port Harcourt, Nigeria. \\ Email gpasting@gmail.com
}

\begin{abstract}
This study compares three conventional methods of natural gas (Associated Natural Gas) dehydration to carry out the dehydration process and suitability of use on the basis of energy requirement. These methods are Triethylene Glycol (TEG) absorption, solid desiccant adsorption and condensation. Analyses performed were based on dehydration of Natural Gas saturated with $10^{3} \mathrm{Nm}^{3} / \mathrm{h}$ water content at a temperature range of $-10^{\circ} \mathrm{C}$ to $30^{\circ} \mathrm{C}$, and gas pressure variation between $7 \mathrm{MPa}$ and $20 \mathrm{MPa}$. This analysis and study showed that energy required for all three processes decreases with increase in pressure, but condensation dehydration requires the least energy at high pressures. Results obtained shows that, both at high pressures and low pressures, TEG dehydration is most suitable and in cases where very low $\mathrm{T}_{\text {dew }}$ is required, solid desiccant adsorption is preferable. In conclusion, the findings in this paper will aid natural gas process design engineers to decide on what method to use base on energy consumption and on the physical and chemical properties of the final products. (C) JASEM
\end{abstract}

http://dx.doi.org/10.4314/jasem.v20i2.4

Keywords: Dehydration, Absorption, Desiccant, Condensation, Triethylene Glycol (TEG)

Natural gas usually contains significant amount of water vapour. Changes in temperature and pressure condense this water vapour, altering the physical state from gas to liquid and then to solid. This water must be removed to protect the system from corrosion and hydrate formation. The distribution specification set the allowable water concentration in natural gas by specifying the dew point temperature $\left(\mathrm{T}_{\text {dew }}\right)$ of natural gas (NG) $\mathrm{T}_{\text {dew }}$ as $-7^{\circ} \mathrm{C}$ at $4 \mathrm{MPa}$, and $\mathrm{T}_{\text {dew }}$ for hydrocarbons is $0^{\circ} \mathrm{C}$ for $\mathrm{NG}$ at the operating pressures (NET4GAS, 2011). This value is equivalent to roughly $5 \mathrm{gH}_{2} \mathrm{O} / \mathrm{m}^{3} \mathrm{NG}$ at $4 \mathrm{MPa}$. The Water content, which $\mathrm{NG}$ at saturation can contain, is dependent on the temperature and pressure within the pipeline and storage facility. The average value of $\mathrm{H}_{2} \mathrm{O}$ in Natural gas is five times higher than requested (GPSA Data Book, 2004).

The distribution specifications depend on the geographic region in which they are applied. For example, in Nigeria water $\mathrm{T}_{\text {dew }}$ should be below $4^{\circ} \mathrm{C}$ for $\mathrm{NG}$ at $4 \mathrm{MPa}$, which means that the $\mathrm{NG}$ can contain more than twice as much water vapors as in Europe (Netusil and Ditl, 2012).

The water content of NG at saturation is dependent on temperature and pressure. With increasing pressure of the gas, the water content decreases, and with increasing temperature the water content in the gas increases (GPSA Data Book, 2004). The water content of the natural gas can be calculated using the equation defined bellow (Gandhidasan, 2003)

$$
W_{\text {water }}=593,335 \exp \left(0.05486 t_{G}\right) P_{G}^{-0.81462}
$$

Where $W_{\text {water }}$ is in kilograms of water per $10^{6} \mathrm{~m}^{3}$ of NG is 2-5 times higher than required.

In order to meet the requirement of a clean, dry and wholly gaseous fuel suitable for transmission through pipelines and distribution for burning by end users, natural gas must go through several stages of processing, which includes removal of entrained liquids, removal of $\mathrm{CO}_{2}, \mathrm{H}_{2} \mathrm{~S}, \mathrm{~N}_{2}, \mathrm{O}_{2}$ and other gases followed by drying to remove water content. In this study the, type of Natural Gas considered are those from Associated Gas (AG). Energy requirement in the dehydration of $A G$ is a major contributor to the cost of operations; it therefore means that efficient energy management must be practice in the dehydration of AG in order to account for energy loss and energy gain. A good account of energy and material balance will create a platform for the selection of Natural Gas dehydration method and efficient design of Natural Gas dehydration plant. Therefore, the objective of the paper is to investigate the different methods of $A G$ dehydration based on total energy consume during the process.

Dehydration Methods: Absorption Dehydration: In this process water is absorbed by Triethyleneglycol 
(TEG). Absorption is done in glycol contactor (tray column or packet bed) by countercurrent flow of wet gas $\left(20-35^{\circ} \mathrm{C}\right)$ and TEG. TEG is enriched (by $\left.\mathrm{H}_{2} \mathrm{O}\right)$ and flows out in the bottom of contactor, then runs through flash and heat exchanger into reboiler. In the reboiler the $\mathrm{H}_{2} \mathrm{O}$ is boiled out. Temperature inside should not exceed $208^{\circ} \mathrm{C}$ due to decomposition temperature of TEG. Regenerated (lean) TEG is then recycled back through heat exchanger and additional cooling unit back into the top of contactor. The processis depicted in the figure below (Bahadori and Vuthaluru, 2009).

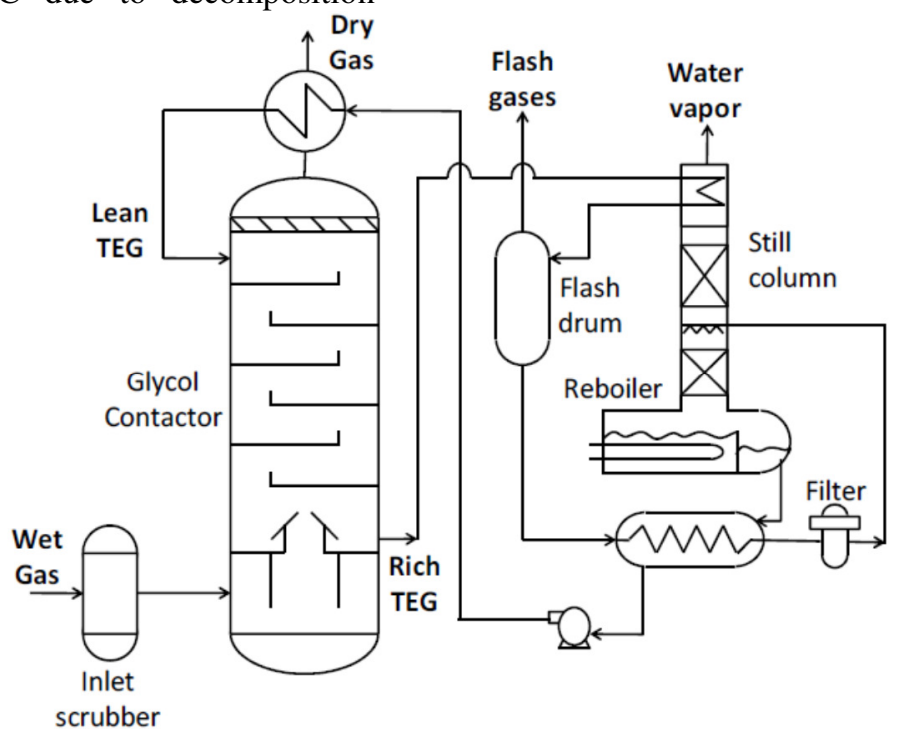

Fig 1: TEG absorption dehydration scheme

Adsorption Dehydration: In this method, solid desiccants adsorb water, most often by mole sieve, silica gel or alumina. As a minimum, two beds systems are used. Typically, one bed is drying gas and the other is being regenerated. Regeneration is done by preheated gas, as it is depicted on the Fig. 2 below or by de- pressurizing (PSA), but that is less often (Netusil and Ditl, 2010).

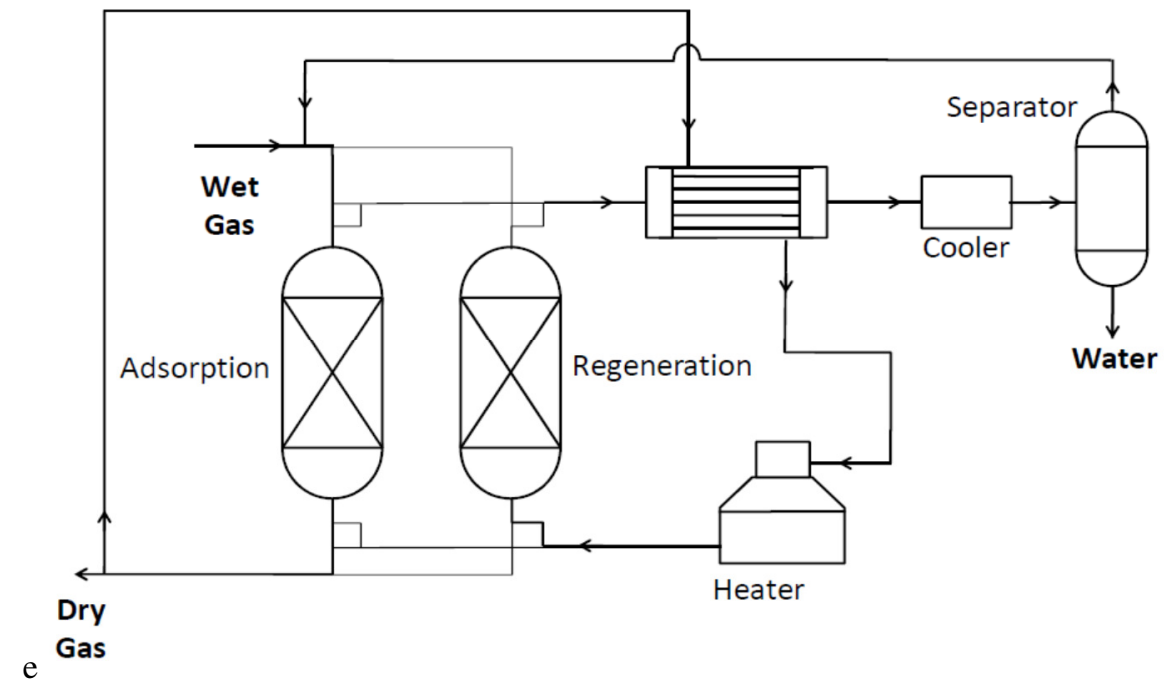

Fig 2: Scheme of temperature swing adsorption dehydration process.

Condensation Dehydration: This method employs gas cooling to turn water molecules into the liquid phase and then removes them from the stream (Guo and Ghalambor, 2005). Natural gas liquids and condensed higher hydrocarbons can also be recovered from natural gas by cooling. The condensation method is therefore usually applied for simultaneous dehydration and recovery of natural gas liquids.

Natural gas can be advantageously cooled using the Joule-Thompson effect (JT effect). The JT effect 
describes how the temperature of a gas changes with pressure adjustment. For NG, thanks to expansion, the average distance between its molecules increases, leading to an increase in their potential energy (Van der Waals forces). During expansion, there is no heat exchange with the environment, and no work creation. Therefore, due to the conservation law, the increase in potential energy leads to a decrease in kinetic energy and thus a decrease in temperature of NG. However, there is another phenomenon connected with the cooling of wet NG, the formation of methane hydrate. Hydrates formed by cooling may plug the flow. This can be prevented by injecting methanol or monoethylenglycol (MEG) hydrate inhibitors before each cooling. Figure 3 depicts an industrial application of dehydration method utilizing the JT effect and MEG hydrate inhibition (Netusil and Ditl, 2012).

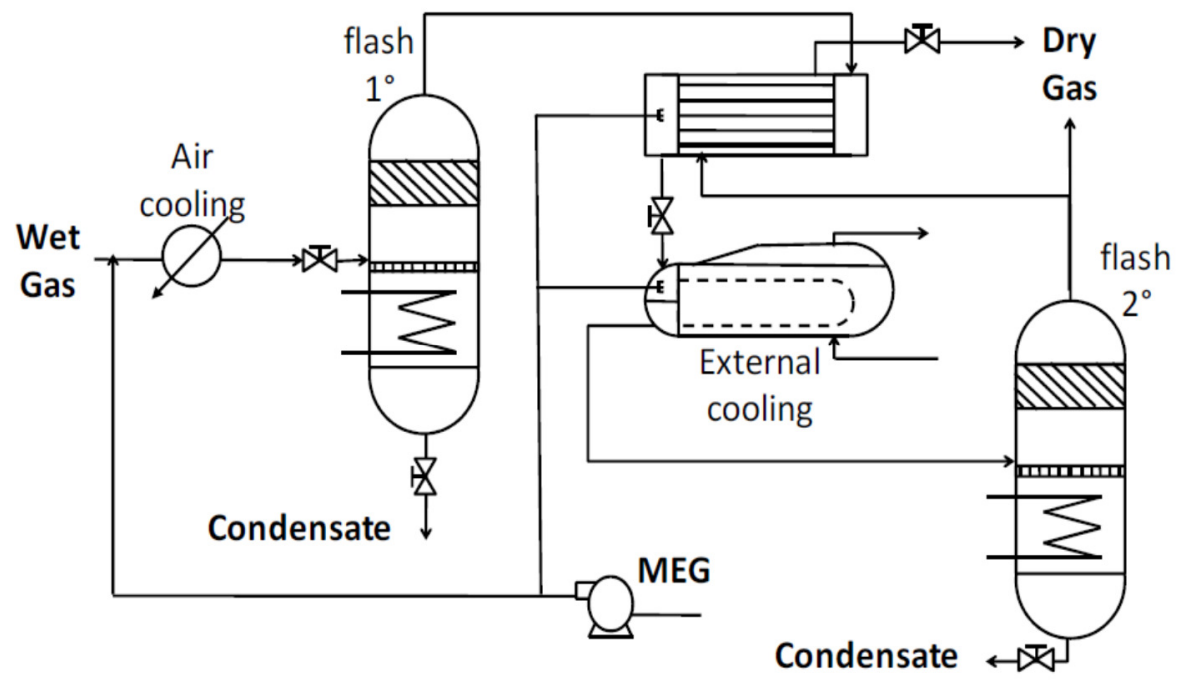

Fig 3: Dehydration method utilizing the JT effect and hydrate inhibition

Each of presented method has its advantages and disadvantages. Absorption by TEG is nowadays the most widely used method and usually reaches the outlet $\mathrm{T}_{\mathrm{dew}}$ around $-10^{\circ} \mathrm{C}$. Furthermore, with improved re- boiler design (Vacuum striping, Drizo, Coldfinger) the outlet $\mathrm{T}_{\text {dew }}$ is even 2-3 times lower. However TEG has a problem with sulfur or higher hydrocarbons contaminated gas, it causes TEG in reboiler to foam and with time is changing into "black mud". Another disadvantage are BTEX emissions in reboiler vent (Hubbard et al, 2000). Adsorption dehydration can achieve very low outlet water concentration $\mathrm{T}_{\mathrm{dew}}<-$ $50^{\circ} \mathrm{C}$ and contaminated gases are not a problem. On the other hand, adsorption requires the highest capital costs and space requirements. Condensation dehydration is the most suitable in cases where a highpressure difference between Underground Storage Gas (USG) and distribution connection is available. However the difference during withdrawal period decreases and when it is insufficient, an external cooling cycle is needed. In addition, a cycle for hydrate inhibitor regeneration (out of liquids separated inside the flashes) is required (Netusil and Ditl, 2012).

\section{MATERIALS AND METHODS}

The models and their calculations are based on the different type of dehydration methods applied in this work. The energy requirement of the three dehydration methods was carry out using a gas flow rate of $90 \mathrm{MMscf} / \mathrm{d}$ at $14.7 \mathrm{psia}$ and $60^{\circ} \mathrm{F}$ from a high pressure separator.

Absorption Dehydration Method: The calculation of TEG absorption is based on GPSA (2004). The natural Gas at 90MMScf/d and $7 \mathrm{MPa}$, was saturated with water at $10^{3} \mathrm{Nm}^{3} / \mathrm{h}$ and allowed to enter the contactor. Water entry rate, TEG circulation rate, lean glycol and heat load at the reboiler are calculated using the equations below.

$$
\begin{aligned}
& \text { Water Entering Rate }\left(\frac{l b m}{h r}\right)=\left(\text { Water Entering }\left(\frac{l b m}{M M S c f}\right)\right)\left(\text { Gas flow rate }\left(\frac{M M S c f}{\text { day }}\right)\right) \quad 1 \\
& \text { TEG Circul Rate }\left(\frac{\text { gal }}{h r}\right)=\left(\operatorname{GalofTEG}\left(\frac{\text { gal }}{\text { lbmH2O entering }}\right)\right)\left(\text { Water Entering Rate }\left(\frac{\text { lbm }}{h r}\right)\right) 2
\end{aligned}
$$




$$
M_{\text {leam }}=\text { Lean Glycol Stream }(99 \%)=\left(\frac{\% w t}{100}\right)\left(\text { TEG Circul Rate }\left(\frac{l b m}{h r}\right)\right)
$$

Sensible heat required for TEG;

$$
Q_{S}\left(\frac{B t u}{h r}\right)=M_{l e a n} C_{p} \Delta T
$$

$\left(C_{p}=0.72 \frac{B t u}{l b m^{\circ} \mathrm{F}}\right)$

Heat required to vapourized water from TEG:

$Q_{v w}\left(\frac{B t u}{h r}\right)=970.3\left(\right.$ water removed $\left.\left(\frac{l b}{h r}\right)\right)\left(\right.$ Gas flow rate $\left.\left(\frac{\text { MMScf }}{\text { day }}\right)\right)$

Heat required to vapourized water from reflux:

$Q_{v r}\left(\frac{B t u}{h r}\right)=0.25 Q_{v w}$

Here we assume $25 \%$ reflux ratio.

Heat load, at the reboiler;

Heat $\operatorname{Load}\left(\frac{B t u}{h r}\right)=\left(Q_{s}+Q_{v w}+Q_{v r}\right)\left(1+\frac{p H L \%}{100}\right)$

Where $p H L \%$ is percentage heat loss. Here, $15 \%$ heat loss was used.

Adsorption Dehydration Method: For adsorption, the design specifications of the adsorber stated in the paper by Netusil and Ditl, (2010), was considered most appropriate for this method. The calculations employed at varying pressure in this method are based on GPSA 2004.

$$
\begin{gathered}
\text { Water Adsorb }\left(\frac{l b m}{h r}\right)=\left(1-\frac{p(\%)}{100}\right) \frac{\left(\operatorname{Gas}\left(\frac{M M S c f}{\text { day }}\right)\right)(\text { Water adsord }(\text { lbm }))\left(\text { Water Entering }\left(\frac{l b m}{M M S c f}\right)\right)}{24} \\
\text { Heat Loss } Q_{h l}\left(\frac{B t u}{h r}\right)=\left(Q_{w}+Q_{s i}+Q_{s t}\right)\left(\frac{p H L(\%)}{100}\right)
\end{gathered}
$$

Where $Q_{w}\left(\frac{B t u}{h r}\right)=$ Heat required to desorb water

$$
\begin{gathered}
Q_{s i}\left(\frac{B t u}{h r}\right)=\text { Heat required to increase bed temperature } \\
Q_{s t}\left(\frac{B t u}{h r}\right)=\text { Heat required to heat the vessel } \\
p H L(\%)=\text { Percentage heat loss. Again, } 15 \% \text { was used }
\end{gathered}
$$

Total heat regeneration duty:

$$
Q_{r}\left(\frac{B t u}{h r}\right)=(2.5)\left(Q_{w}+Q_{s i}+Q_{s t}+Q_{h l}\right)
$$

The 2.5 factor correct for the changes in Temperature difference across the bed with time during the regeneration cycle (GPSA, 2004). 
Condensation Dehydration Method: The total heat energy for the condensation dehydration method, was calculated based on industrial data and supplementary calculation was done using the Joule-Thomson Effect. The total heat energy is the sum of the heat energy in the air pre-cooling unit, external cooling unit pumps for injecting Methyl Ethylene Glycol (MEG), MEG regeneration heat, and flash heating.

Graphical plot was generated and then use to compare the three methods of gas dehydration processes.

\section{RESULTS AND DISCUSSION}

Absorption Dehydration: The lean TEG concentration is $99 \%$ and the rich TEG temperature entering the regenerator is $302^{\circ} \mathrm{F}$. The reboiler temperature is $410^{\circ} \mathrm{F}$
Table 1: Energy Requirement for Absorption Dehydration Process

\begin{tabular}{cc}
\hline Parameters & $\begin{array}{c}\text { Heat Requirement } \\
\left(\mathrm{x} 10^{3} \mathrm{Btu} / \mathrm{hr}\right)\end{array}$ \\
\hline $\mathrm{Q}_{\mathrm{s}}$ & 275.397 \\
$\mathrm{Q}_{\mathrm{vw}}$ & 78.849 \\
$\mathrm{Q}_{\mathrm{vr}}$ & 19.712 \\
Heat Loss & 56.0937 \\
Total Heat Load & 430.0517 \\
\hline
\end{tabular}

Adsorption Dehydration: The calculation of the energy requirement for the adsorption dehydration method was based on the parameters in the design specification presented in Netusil and Ditl, (2010). Using Equation 8 to 10, Table 2 shows the results of the various component of the total heat regeneration duty. The results are compared with those of GPSA, (2004), Gandhidasan (2001), and Kumar (1987).

Table 2: Energy Requirement for Adsorption Dehydration Process

\begin{tabular}{cccc}
\hline Parameters & $\begin{array}{c}\text { Heat Requirement } \\
(\mathbf{x 1 0} \mathbf{B} \mathbf{B t} / \mathbf{h r})\end{array}$ & $\begin{array}{c}\text { Compared Values } \\
\left(\mathbf{x 1 0} \mathbf{3}^{\mathbf{3}} \mathbf{B t u} / \mathbf{h r}\right)\end{array}$ & Authors \\
\hline $\mathbf{Q}_{\mathbf{w}}$ & 144.72 & 729.72 & GPSA \\
$\mathbf{Q}_{\text {si }}$ & 70.1099 & 518.64 & Gandhidasan \\
$\mathbf{Q}_{\text {st }}$ & 50.524 & 580.06 & Kumar \\
Heat Loss & 26.535 & & \\
Total Heat Load & 729.72 & & \\
\hline
\end{tabular}

Condensation Dehydration: In the condensation process, water is remove from the Natural Gas stream by cooling the gas through an expansion valve (JouleThomson Effect). The amount of water remove is dependent on the pressure difference between the inlet gas stream and the outlet gas stream. The Natural Gas (90MMScf/d) is throttle through the expansion valve at varying inlet pressures from $7 \mathrm{MPa}$ to $20 \mathrm{MPa}$. The outlet pressure is control such that MEG was continually injected into the inlet stream to prevent hydrate formation in the system. A MEG rate of 386 gal/hr was used. Result obtained are shown in Table 3.

Analysis of Results: Energy consumption is a major factor that contributes to increase in operating cost. Natural Gas process design Engineers are aware of this and they tend to reduce energy consumption via efficient energy management, without compromise to product quality, environment, health and safety of personnel. The best selection from available design alternatives, based on design parameters and available industrial data, help in efficient energy management.

A close look at Fig. 4 shows that at reduced pressure, condensation dehydration method with MEG injection, consumes more energy above $300 \times 10^{3} \mathrm{Btu} / \mathrm{hr}$ at pressure below $10 \mathrm{MPa}$. This is in perfect agreement with value obtained in the plot generated by Netusil and Ditl, (2012). One attendant effect is thermal weakening of process facility. As pressure decrease, energy consumption decrease linearly.

Although, the total energy consumption for the adsorption dehydration method is higher than that of absorption method, but it seems that the cause of their energy consumption are almost the same, as can be clearly seen in Fig.4.

At 16.4MPa, energy consumption for Adsorption and Condensation dehydration method are the same of about $145 \times 10^{3} \mathrm{Btu} / \mathrm{hr}$, which is higher than Absorption dehydration, which is about $100 \times 10^{3} \mathrm{Btu} / \mathrm{hr}$ at the same pressure. In comparison with data obtained by Netusil and Ditl (2012), at the same pressure total energy consumed for Adsorption was $426.517 \times 10^{3} \mathrm{Btu} / \mathrm{hr}$ and $272.971 \times 10^{3} \mathrm{Btu} / \mathrm{hr}$ for Absorption.

At pressure of $20 \mathrm{MPa}$ (2915psia), the total energy consumption for Absorption is about $85 \times 10^{3} \mathrm{Btu} / \mathrm{hr}$ and for Adsorption is about $132 \times 10^{3} \mathrm{Btu} / \mathrm{hr}$, making Absorption dehydration method more preferable in removing water form $\mathrm{AG}$ 
Table 3: Energy Requirement for Condensation Dehydration Process

\begin{tabular}{ccccc}
\hline \multicolumn{5}{c}{ Parameters $\left(\mathrm{x} 10^{3} \mathrm{Btu} / \mathrm{hr}\right)$} \\
\hline $\begin{array}{c}\text { Pressu } \\
\text { re }\end{array}$ & $\begin{array}{c}\text { MEG and } \\
\text { Condensate } \\
\text { Pump }\end{array}$ & $\begin{array}{c}\text { MEG } \\
\text { Regeneration }\end{array}$ & $\begin{array}{c}\text { Flash } \\
\text { Heating }\end{array}$ & Total \\
(Mpa) & & & & \\
$\mathbf{7}$ & 47.77 & 218.37 & 174.01 & 440.16 \\
$\mathbf{1 0}$ & 17.06 & 170.60 & 102.36 & 290.03 \\
$\mathbf{1 5}$ & 16.41 & 109.18 & 37.53 & 163.13 \\
$\mathbf{2 0}$ & 9.21 & 58.00 & 19.92 & 87.14 \\
\hline
\end{tabular}

Gandhidasan, P, Al-Farayedhi, A., and Al-Mubarak, A. (2001) Dehydration of natural gas using solid desiccants. Energy 26: 855-868.

Gandhidasan, P. (2003). Parameter Analysis of Natural Gas Dehydration by Triethylene Glycol Solution. Energy 26: 855-201.

GPSA (2004) Engineering Data Book. 12th ed. Tulsa: GPSA Press.

Guo, B. and Ghalambor, A. (2005). Natural Gas Engineering Handbook, Gulf Publishing, Houston, Texas, USA.

Hubbard R.A. and Campbell J.M. (2000). An Appraisal of Gas Dehydration Process. Hydrocarbon Engineering 5: 71-74.

Kumar, S (1987) Gas Production Engineering. Houston: Gulf Professional Publishing 239.

NET4GAS (2011) Gas quality parameters. Available at:http://extranet.transgas.cz/caloricity_spec.aspx

Fig 4: Graphical Comparison of the Total Energy

Consumed By the Three Methods

Conclusion: Based on the total energy consumed by each method of AG dehydration process, it is more economical to use Absorption dehydration method to remove water from Associated Gas. The simple reason is that it consume less energy both at high and low pressures. This justify the fact that in Natural Gas Processing industry, absorption dehydration is frequently applied in dehydrating Associated Natural Gas.

\section{REFERENCES}

Bahadori, A. and Vuthaluru, H.B. (2009). Simple Methodology for Sizing of Absorbers for TEG Gas Dehydration Systems. Energy 34: 19101916.
Netusil, M. and Ditl, P. (2010). Comparison of Methods for Dehydration of Natural Gas Stored in Underground Storage, Journal of Applied Chemistry 49(2): 87-88.

Netusil M, Ditl P (2011) "Comparison of Three Methods for Natural Gas Dehydration, Journal of Natural Gas Chemistry 20, $471-476$.

Netusil, M. and Ditl, P. (2012), Natural Gas Dehydration. INTECH, Czech Technical University, Prague, Czech Republic. 